\title{
Periodic vs. Molecular Cluster Approaches to Resolving Glass Structure and Properties: Anorthite a Case Study
}

\author{
Kun V. Tian, ${ }^{1,2}$ Mustafa Z. Mahmoud, ${ }^{3}$ Paola Cozza, ${ }^{4}$ Silvia Licoccia, ${ }^{2}$ De-Cai Fang, ${ }^{5}$ Devis Di Tommaso, ${ }^{3,}{ }^{*}$ Gregory \\ A. Chass, ${ }^{3,}{ }^{,}$G. Neville Greaves $6,7,8$
}

${ }^{1}$ Materials Science Research Institute, Faculty of Dentistry, Semmelweis University, Budapest 1088, Hungary

${ }^{2}$ Department of Chemical Science and Technologies and Centro NAST, University of Rome Tor Vergata, Via della Ricerca Scieniifica 1, 00133 Roma, Italy

${ }^{3}$ School of Biological and Chemical Sciences, Queen Mary University of London, London E1 4NS, United Kingdom

${ }^{4}$ Department of Medicine and Centro NAST, University of Rome Tor Vergata, Via della Ricerca Scieniifica 1, 00133 Roma, Italy

${ }^{5}$ College of Chemistry, Beijing Normal University, Beijing 100875, People's Republic of China

${ }^{6}$ Institute of Mathematics, Physics and Computer Science, Aberystwyth University, Aberystwyth SY23 3BZ, United Kingdom

${ }^{7}$ State Key Laboratory of Silicate Materials for Architectures, Wuhan University of Technology, Wuhan 430070, P. R. China

${ }^{8}$ State Department of Materials Science and Metallurgy, University of Cambridge, 27 Charles Babbage Road, Cambridge CB3 OFS, UK

\begin{abstract}
:
Periodic and molecular cluster models are presented for anorthite $\left(\mathrm{CaAl}_{2} \mathrm{Si}_{2} \mathrm{O}_{8}\right)$, a cement forming glass with desirable thermal and mechanical properties also tested in dental applications. Both the crystalline and amorphous structures were characterised by ab initio molecular dynamics and found to be in good agreement with experiment. Additional investigations of the elongation and fracture of the glass were also made. The recovery of material properties signaled the failure of the periodic method to generate acceptable fracture surfaces to model cement forming-sites. Isolated molecular cluster models of anorthite ( 300 atoms) and hydrated anorthite were therefore investigated with electronic structure methods and showed sound structural matches with the traditional periodic structures. The equilibrated clusters were used to develop cement models, through binding of short acid oligomers to selected Al-centres, simulating the glass-polymer interface. Overall, the anorthite glass structures emerging from periodic and cluster models were in close agreement. Results suggest that bare molecular cluster models represent an alternative avenue for accurately investigating amorphous systems, providing more realistic descriptions of edge and corner sites, as well as as interfaces.
\end{abstract}

Keywords: anorthite; cement; ab initio molecular dynamics; cluster model; EXAFS

\section{INTRODUCTION}

Anorthite (An), an calcium rich compositional variety of plagioclase feldspar minerals found in the lower crust of the earth and igneous rocks, ${ }^{1}$ is also the main component of the lunar highlands. ${ }^{2}$ Its calcium aluminosilicate composition $\left(\mathrm{CaAl}_{2} \mathrm{Si}_{2} \mathrm{O}_{8}\right)$ equilibrates in both crystalline and amorphous forms. ${ }^{3}$ Glasses based on anorthite are widely used for display screens, whilst An-glass-ceramic systems find specific medical function as implants ${ }^{4}$ and tooth/bone restorations, ${ }^{5}$ as well as in technological applications including insulators ${ }^{6}$ and electronic substrates (low temperature co-fired ceramic substrate) ${ }^{7}$ due to low dielectric constants, good co-fireability with other materials, and low cost. ${ }^{7,8}$ Of particular interest is the cement-forming properties of anorthite glasses, having been trialled in biocompatible ionomer cements for dental use ${ }^{9}$ and cements with reduced $\mathrm{CO}_{2}$ emission relative to traditional binder materials (i.e. Portland)..$^{10}$ Anorthite is also used in temperature stable geothermal cements for high temperature applications ${ }^{11,12}$ and in firebrick, ${ }^{13}$ due to its potential for ultra-low thermal conductivity. ${ }^{12}$ It is used in geologic $\mathrm{CO}_{2}$ sequestration to reduce anthropogenic $\mathrm{CO}_{2}$ emmision and mitigate global climate change. ${ }^{14}$ Further, it serves as an ethical replacement for natural bone-ash in superior whitewares such as Bone china. ${ }^{15}$

However, An is a relatively rare mineral outside of the Earth's mantle and lower crust due to its relatively low weathering potential. Although limited amounts are sourced from volcanic sources for study, ${ }^{16}$ synthetic forms are most often employed; ${ }^{1}$ often prepared via sol gel processing ${ }^{17}$ and firing at $1250{ }^{\circ} \mathrm{C},{ }^{18}$ or from waste materials, such as a combination of spent hydroprocessing catalysts and furnace slag. ${ }^{19}$ Deviations in mechanical, optical and electrical properties of synthetic An relative to natural forms are of historic and continuing interest. ${ }^{15,}$ 20-25

For earth sicence purpose, An crystals are usually examined under compression to reveal their polymorphs. ${ }^{26-28}$ The structure of An glass has been studied with X-ray diffraction, ${ }^{29}$ Raman spectroscopy and neutron scattering and it was proposed that the glass is composed of four-membered rings of $\mathrm{TO}_{4}$ tetrahedra ( $\mathrm{T}=$ $\mathrm{Si}$ or $\mathrm{Al}){ }^{3}$ interspersed with $\mathrm{Ca}$ compensating $\mathrm{Al}$ tetrahedra. ${ }^{23}$ The glass transition has been studied with classical molecular dynamics simulation, ${ }^{30-32}$ as well as the liquid form of $\mathrm{An}^{33,34}$ however no work to-date has computationally characterised solid An, or An clusters.

Crystalline and amorphous materials are most often modelled through periodic treatment, such as periodic boundary condition methods (PBC), where a defined unit cell is repeated in 3-Dimenions to represent the bulk; 2-D 'slices' being used to generate surfaces. These are, by definition crystal-like at the range of the unit cell size, and wholly defect free; else identical defects are mirrored in each unit cell - far from appropriate representations of the physical reality. This is exasperated in explorations of nonstable conditions, where periodic and fracture-surfaces unphysically model retaining, or recovering post-fracture, their full and original mechanical properties. ${ }^{35}$

An alternative is the embedded cluster molecular cluster (EC-MC) approach, which emerged from generating ionic models, ${ }^{36}$ embeds a chosen cluster of atoms or ions free to move in a larger frozen/fixed crystalline lattice described in a periodic manner. The environment was originally described as a set of point charges, and was successful in predicting structure and selected properties in systems difficult to characterise by standard techniques. ${ }^{36}$ More recently, the embedded clusters based on full quantum descriptors have dramatically raised the accuracy of such EC-MC models in the characterisation of materials at reasonable computational costs. ${ }^{37}$ In particular, $a b$ initio and density functional theory (DFT) methods employed to EC-MC models have been successful in reproducing bonding properties, $^{38}$ describing surface adsorption, ${ }^{39-42}$ diffusion, ${ }^{43}$ as well as heterogeneous catalysis by 
transition metals ${ }^{44,45}$ and zeolites. ${ }^{46-53}$ The EC-MC method has also been successesful in describing graphene functionalisation ${ }^{54}$ and the electronic structures of semiconductors. ${ }^{55-62}$ When effects of host environment are accounted-for in the models, effects not previously observed may be resolved. ${ }^{41}$

The molecular cluster may be 'unembedded', effectively decoupled from its surrounding lattice, and studied as a bare molecular cluster (BMC). BMC's show promise of being a complementary tool and model in the characterisation of materials, for nano-clusters/particles in particular, once standing problems are resolved. Originally explored to reduce computational demand, or to isolate specific for the fullerene family and few-atomic clusters of less active metals. ${ }^{63-65}$ Currently this is the least common method employed and the most difficult to manage successfully in the modelling of material systems. Problems arise at interfaces, with descriptions of how to 'cap' the cluster and what terminal groups to use; often accomplished with terminal $\mathrm{H}$-atoms or $-\mathrm{OH}$ groups. ${ }^{41,66-}$ ${ }^{69}$ This may result in a non-realistic environments for the atoms in the BMC, relative to the real material systems, potentially perturbing their physical and chemical behaviours. ${ }^{70,71}$ Additionally, the terminal groups have freedom to move and thus are more floppy, ${ }^{72}$ resulting in flattened hypersurfaces for BMCs, effectively requiring an average of $5-10 \%$ more computational resources than a similarly-sized EC-MC. ${ }^{73}$ Current limitations of BMCs restrict dimensions of cluster to $\sim 2-3 \mathrm{~nm}$ which curtail electrostatic force descriptions to within these dimensions, and thus the absence of longer-range contributions may underestimate binding energies.

However, despite these limitations, BMCs show promise due to their approaching the sizes and SA:V(surface area:volume) ratios of nano-clusters (a key asset), in addition to being able to most accurately reproduce the structure and dynamics of interfaces as well as surface, edge and corner sites, where reactivity and materials properties originate. Recent works employing BMC approaches have shown success for modelling adsorption of single atoms (sodium, barium, and copper) on $\mathrm{Na}(110)$, $\mathrm{Ba}(110)$ and $\mathrm{Cu}(100)$ surface respectively, ${ }^{74}$ nuclear quadrupole coupling constant in glasses, ${ }^{75}$ surface electronic structure of Titanium Carbide, Vanadium Carbide, and Titanium Nitride. ${ }^{76}$

This encouraged us to initiate characterisation and comparison of PBC and BMCs, of anorthite glass in addition to exploring BMCs for cement formation at glass interfaces. We employed a novel BMC approach, with clusters of $\sim 1.2-1.7 \mathrm{~nm}$ a side $\left(\mathrm{V} \sim 2.5-3.0 \mathrm{~nm}^{3}\right)$ to resolve atomistic structure, energetics and dynamics at interfaces.

\section{METHODS}

\section{Solid-state DFT calculations}

Wainwright and Starkey's anorthite $\left(\mathrm{CaAl}_{2} \mathrm{Si}_{2} \mathrm{O}_{8}\right)$ triclinic crystal structure (space group P-1), ${ }^{77}$ was employed as a starting geometry to conduct total energy and structural calculations with the CASTEP program (v.7.03), which implements density functional theory (DFT) using a planewave (PW) basis set and pseudopotential approach. ${ }^{78}$ The
Perdew-Burke-Ernzerhof (PBE) generalised gradient approximation (GGA) was employed for the exchange and correlation terms, ${ }^{79}$ whilst Vanderbilt ultrasoft pseudopotentials ${ }^{80}$ represented core-valence interactions for all atomic species. Plane-wave cutoffs for the smooth part of the wavefunction and k-point separation for the Monkhorst-Pack grid were set to $340 \mathrm{eV}$ and $0.04 \AA^{-1}$, respectively. Full structural optimizations (both cell and atomic positions) of anorthite crystal were performed in the absence of any symmetry operators (i.e., in space group P1). Lattice parameters and internal atomic coordinates were independently modified to minimize the total energy and interatomic forces. The BroydenFletcher-Goldfarb-Shanno scheme was used for ions and cell relaxation. The criteria for the variable-cell minimisation were selected as follows: difference in total energy within $10^{-5} \mathrm{eV}$ atom ${ }^{-1}$, maximum ionic HellmannFeynman forces within $0.03 \mathrm{eV} \AA^{-1}$, maximum displacement within $10^{-3} \AA$, and maximum stress within $0.05 \mathrm{GPa}$.

\section{Ab initio molecular dynamics}

$A b$ initio (Born-Oppenheimer) molecular dynamics (AIMD) simulations of the amorphous and crystalline forms of anorthite were conducted with the electronic structure code CP2K/Quickstep code, version 2.7. ${ }^{81}$ CP2K implements density functional theory (DFT) based on a hybrid Gaussian plane wave approach. ${ }^{82}$ The PBE was used for the exchange correlation as previous studies have shown PBE makes accurate predictions of the structural, dynamical and electronic properties of and alumino-silicate glasses. ${ }^{83-85}$ Goedecker-Teter-Hutter pseudopotentials ${ }^{86}$ were used to describe the corevalence interactions. All atomic species were represented using a double-zeta valence polarized basis set. The plane wave kinetic energy cut off was set to 1000 Ry. $k$-sampling was restricted to the $\Gamma$ point of the Brillouin zone. Simulations were carried out with a wave function optimization tolerance of $10^{-6}$ au that allows for $1.0 \mathrm{fs}$ time steps with reasonable energy conservation. Periodic boundary conditions were applied throughout.

$M D$ simulations on the crystalline phase started from the full-optimized unit cell of the triclinic structure of anorthite, and were conducted under an NVT ensemble (constant Number of particles, Volume, and Temperature) using a Nosé-Hoover chain thermostat to maintain the average temperature at $\mathrm{T}=300 \mathrm{~K}$. Statistics were then collected for a period of $30 \mathrm{ps}$.

The initial configuration of the amorphous phase was generated by randomly placing 156 constituent anorthite atoms $\left(\mathrm{Ca}_{12} \mathrm{Al}_{24} \mathrm{Si}_{24} \mathrm{O}_{96}\right)$ in a cubic unit cell of length $12.5524 \AA$, which corresponds to the density of the optimised unit cell of anorthite crystal $\left(2.80 \mathrm{~g} \mathrm{~cm}^{-3}\right)$. Interatomic minimum distance constraints of $1.45 \AA$ for $\mathrm{Si}-\mathrm{O}$ and $\mathrm{Al}-\mathrm{O}, 2.10 \AA$ for $\mathrm{Ca}-\mathrm{O}$, and $2.60 \AA$ for all other atomicpairs were also imposed to avoid unphysical short distances between the atoms. The resultant structure was first subject to 40 steps of geometry optimisation, which relaxed strain imposed by randomization, and then to a robust and well-tested "full" AIMD melt-and-quench simulation protocol, ${ }^{87,88}$ which comprised a series of NVT 
runs of approximately 20 ps each starting from $3000 \mathrm{~K}$ down to $600 \mathrm{~K}$ at $300 \mathrm{~K}$ interval. Finally, at $300 \mathrm{~K}$ the glass were allowed to equilibrate (production phase) for $30 \mathrm{ps}$. The cubic unit cell of the final room temperature bulk glass configuration was isotropically relaxed to obtain the optimal (theoretical) density of anorthite glass, $2.77 \mathrm{~g} \mathrm{~cm}^{-}$ 3 , which is $\sim 1 \%$ lower than the starting density and $\sim 2 \%$ higher than the experimental value $\left(2.70 \mathrm{~g} \mathrm{~cm}^{-3}\right) .89,23$

Atomic arrangements of the anorthite crystal and of the structure of anorthite glass are shown Figure 1.

\section{Static quantum molecular cluster models}

A bare molecular cluster (BMC) model of anorthtite was constructed from the structure as determined by neutron diffraction; accessed from the American Minerlogist Crystal Structure Database, (_database_code amcsd 0019663). Anorthite composition $\left(\mathrm{CaAl}_{2} \mathrm{Si}_{2} \mathrm{O}_{8}\right)$ was retained during periodic to finite structure conversion. The An cluster was then enveloped with $36 \mathrm{H}$ atoms, effectively capping severed bridging $O$ links between unit cells, forming terminal $\mathrm{OH}$ groups on $\mathrm{Si}$ and $\mathrm{Al}$ and mimicking interfacial $\mathrm{OH}$-rich $\mathrm{Al}$-sites most susceptible to polymer acid-attack at glass surfaces. O-stoichiometry was upheld through addition of 2 explicit $\mathrm{H}_{2} \mathrm{O}$ molecules, to the cluster. The resultant cluster consisting of 8 anorthite units $\left(\mathrm{Ca}_{8} \mathrm{Al}_{16} \mathrm{Si}_{16} \mathrm{O}_{64} \mathrm{H}_{40}, 164\right.$ atoms), was geometry-optimised, with analytical frequencies determined at the B3LYP/DGDZVP level of theory (Figure $6)$.

This stable glass particle served as a substrate on which to build two representative cement models. Oligomers of polyacrylic acid (PAA) were attached to the glass via Al linkages. This first 'large' cement model included three PAA moieties ( 1 heptamer, 1 hexamer, 1 tetramer -158 atoms) attached to the stable glass particle making a 322 atom-cluster). This was subsequently geometryoptimised using the ab initio Hartree-Fock (HF) method and a 3-21G pople basis set (1942 electrons, 2292 basis functions), in gas-phase (Figure 7). A second 'small' model was pruned from the optimised geometry of the 'large' model, retaining the PAA heptamer (64 atoms) bound via a square-based-pyramidal (SBP) Al-V linkage; the hexaand penta-mers were removed to make a more computationally-manageable cluster (Figure 8). The resultant cementitious cluster consisted of 228 atoms and was geometry-optimised, employing the DFT Becke-3Lee-Yang-Parr correlation (B3LYP) method, ${ }^{90,91}$ and an allelectron DGDZVP basis set. ${ }^{92}$ The resultant computations were at the limit of current capabilities of computational workstations (1562 electrons, 2750 basis functions).

Calculations were performed using the Gaussian 09 program package..$^{93}$ All structures were geometryoptimised and confirmed, by analytical frequency computations, as residing at a minimum on their respective potential energy hypersurfaces (PEHSs).

\section{RESULTS AND DISCUSSION}

\section{Bulk structural properties}

Figure 1 reports the structures of the optimised unit cell of An crystal and of the annealed and isotropically-relaxed structure of An glass. One of the most relevant structural differences between crystalline and amorphous forms of


Figure 1. Views of the optimised unit cell of anorthite crystal (left), and of the annealed and isotropically relaxed structures of the anorthite glass (right).

An is that the crystal is composed of four-membered rings of $\mathrm{TO}_{4}$ tetrahedra ( $\mathrm{T}=\mathrm{Si}$ or $\left.\mathrm{Al}\right)$, whereas the glass comprises a mixture four-, five- and six-membered rings containing $\mathrm{SiO}_{4}$ and $\mathrm{AlO}_{x}(x=4,5)$ species. In order to quantify the differences between the short-range structural properties of An crystal and glass, we computed the radial distribution functions (RDFs) and angular distribution functions (ADFs) of the network formers, $\mathrm{Si}$ and $\mathrm{Al}$, and of the network modifier, $\mathrm{Ca}$, with the oxygen atoms.

Crystal and glass RDFs for $\mathrm{Si}-\mathrm{O}$ are both characterised by a well-defined peak centred at $1.64 \AA$ (Figure 2), whilst the average $\mathrm{Al}-\mathrm{O}$ distance increases $1.76 \rightarrow 1.79 \AA$ (crystal $\rightarrow$ glass) with a near-doubling of the peak's fullwidth-half-maximum (FWHM) value $(0.08 \rightarrow 0.14 \AA$, crystal $\rightarrow$ glass). The average $\mathrm{Ca}-\mathrm{O}$ distance in the glass is $2.38 \AA$, a little lower than in the crystal, with an average coordination number close to 7 ; in agreement with EXAFS (Figure 3$)^{23}$ and computational studies of glasses containing Ca. ${ }^{94}$

Similar observation of short-range structural variations comes from the analysis of the $\mathrm{O}-\mathrm{Si}-\mathrm{O}$ and $\mathrm{O}-\mathrm{Al}-\mathrm{O}$ bond angle distributions (Figure 4). For both the crystalline and

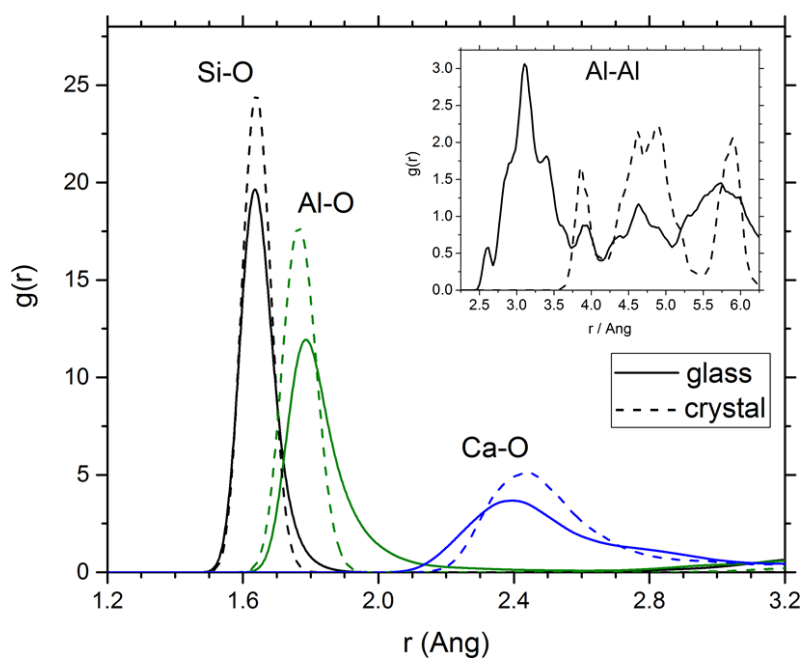

Figure 2. $\mathrm{Si}-\mathrm{O}, \mathrm{Al}-\mathrm{O}$ and $\mathrm{Ca}-\mathrm{O}$ radial distribution functions, $\mathrm{g}(\mathrm{r})$, for the crystalline and glassy forms of anorthite. 

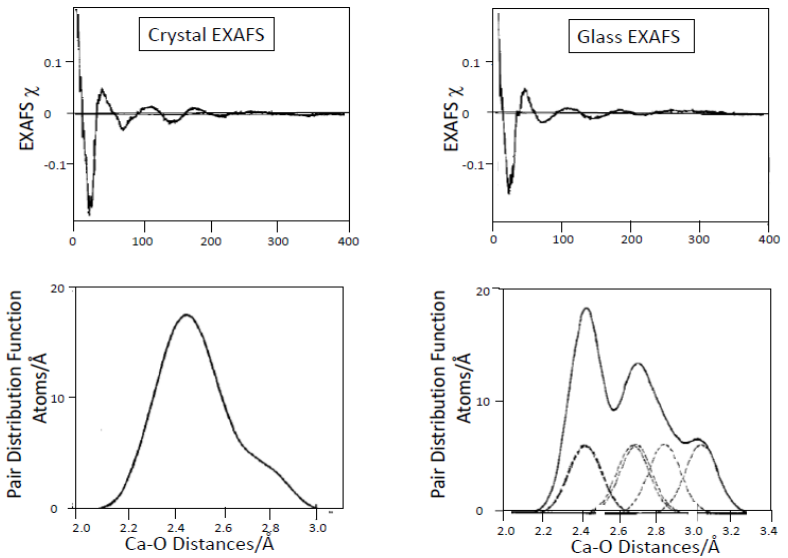

Figure 3. Ca K-edge EXAFS for anorthite crystal (left) and anorthite glass (right), with oxygen shell pair distributions. Reproduced from ref 23 (C) Springer-Veelag 1985.

amorphous phases, the $\mathrm{O}-\mathrm{Si}-\mathrm{O}$ ADF is narrowly distributed around the tetrahedral angle $\left(\sim 109.5^{\circ}\right)$. In contrast, the $\mathrm{O}-\mathrm{Al}-\mathrm{O}$ angle distribution in the glass is shifted toward lower values and the FWHM $\left(35^{\circ}\right)$ is twice that in the $\mathrm{O}-\mathrm{Al}-\mathrm{O}$ of the crystal. This suggests an increase of atomic flexibility in the glass at the aluminium pivots ${ }^{95,96}$ which relates to the presence of $\mathrm{Al}-\mathrm{Al}$ as well as $\mathrm{Al}-\mathrm{Si}$ correlations (Lowensteinian disorder), which is known to occur in aluminiosilicate glasses. ${ }^{97}$ Lowenstein's Rule, which recognizes the absence of Al-Al correlations in feldspar crystals, is generally not exclusively obeyed in equivalent glasses which include odd-membered as well as even-membered rings. The bond angle distribution of $\mathrm{Al}-\mathrm{O}-\mathrm{Al}$ in the inset of Figure 4 is characterised by two peaks. Analysis of the coordination around $O$ (with Al) shows that the peak centred at $120^{\circ}$ is associated to familiar Al-O-Al angle around an oxygen atom that is coordinated to two Al. On the other hand, the peak at $95^{\circ}$ is due in part to $8 \%$ of the oxygen atoms being therecoordinated to $\mathrm{Al}$ forming triclusters. ${ }^{23}$ By contrast, there are no tri-clusters coordinated to $\mathrm{Si}$ in this An glass structure.



Figure 4. $\mathrm{O}-\mathrm{Si}-\mathrm{O}$ and $\mathrm{O}-\mathrm{Al}-\mathrm{O}$ angular distribution functions for the crystalline and glassy forms of anorthite.
The different structural behaviour of the network formers is also evidenced by the distribution of the coordination number of $\mathrm{Si}$ and $\mathrm{Al}$, wherein $\mathrm{Si}$ atoms have very rigid tetrahedral coordination environs $(\mathrm{CN}=4)$. Similarly, Al atoms in the crystal also prefer a tetrahedral molecular geometry (Figure 1 ), yet this increased to $\sim 4.4$ oxygen atoms in the glass, with a significant amount (27\%) of $\mathrm{Al}(\mathrm{V})$ species.

Likewise, Ca exhibits a distribution of sites, with an average coordination number of 7 , as reported in the early EXAFS experiments, ${ }^{23}$ reproduced in Figure 3 . In particular, the average $\mathrm{Ca}-\mathrm{O}$ pair distribution function found for the glass is very similar to that of An itself, both in width and peak position. ${ }^{23}$ AIMD calculations reproduce similar geometries for the crystalline and glassy states (Table 1).

Table 1. Average Ca-coordination number and distances $r_{\text {peak }}(\AA)$ of the $1^{\text {st }}$ peak of the $\mathrm{Ca}-\mathrm{O}$ pair distribution functions and obtained from the AIMD simulations and EXAFS studies ${ }^{23}$ of anorthite crystal and glass.

\begin{tabular}{ccccc}
\hline & \multicolumn{2}{c}{ AIMD } & \multicolumn{2}{c}{ EXAFS } \\
\hline & $\begin{array}{c}\text { Coord. } \\
\text { Number }\end{array}$ & $\begin{array}{c}\mathrm{r}_{\text {peak }} \\
(\AA)\end{array}$ & $\begin{array}{c}\text { Coord. } \\
\text { Number }\end{array}$ & $\begin{array}{c}\mathrm{r}_{\text {peak }} \\
(\AA)\end{array}$ \\
\cline { 2 - 5 } Anorthite Crystal & 7.2 & 2.44 & 7.0 & 2.43 \\
Anorthite Glass & 7.0 & 2.38 & 7.0 & 2.42 \\
\hline
\end{tabular}

\section{Surface modelling}

The method that has been employed to date in order to model the surfaces of amorphous systems is the "supercell" multislab approach developed to study crystalline solid surfaces. In this method, the unit cell consists of a finite number of atomic layers parallel to a given crystallographic plane, which together create a slab, and a vacuum layer that is repeated periodically in all three dimensions. However, multicomponent amorphous systems are characterised by the absence of obvious cleavage planes.

Consequently, multislab surface models of amorphous systems have been to-date simulated by cutting the structure of the bulk glass along arbitrary directions. ${ }^{99,100}$ The "supercell" approach does not guarantee the generation of the most stable surface, as highly reactive arrangements of the superficial atoms, such as twocoordinated $\mathrm{Si}$ or isolated $\mathrm{O}$ atoms. These are obtained, for example, by cleaving two or more $\mathrm{Si}-\mathrm{O}$ bonds on the same superficial silicon atom during the cutting process. ${ }^{98}$

Sushko and co-workers have recently proposed a computational procedure to generate structural surface models of the complex crystalline ionic material $12 \mathrm{CaO} \cdot 7 \mathrm{Al}_{2} \mathrm{O}_{3}$ (mayenite). ${ }^{35}$ This procedure involves simulating lattice rupture under the influence of an external strain along a certain axis until the material breaks and forms energetically stable arrangements of the surface atoms.

We have applied this methodology to attempt the generation of an unbiased stable surface of anorthite glass. Figure 5 shows the potential energy of anorthite glass as a function of the lattice constant along the $z$ axis (c) while the values of the lattice constants in the $x-y$ 


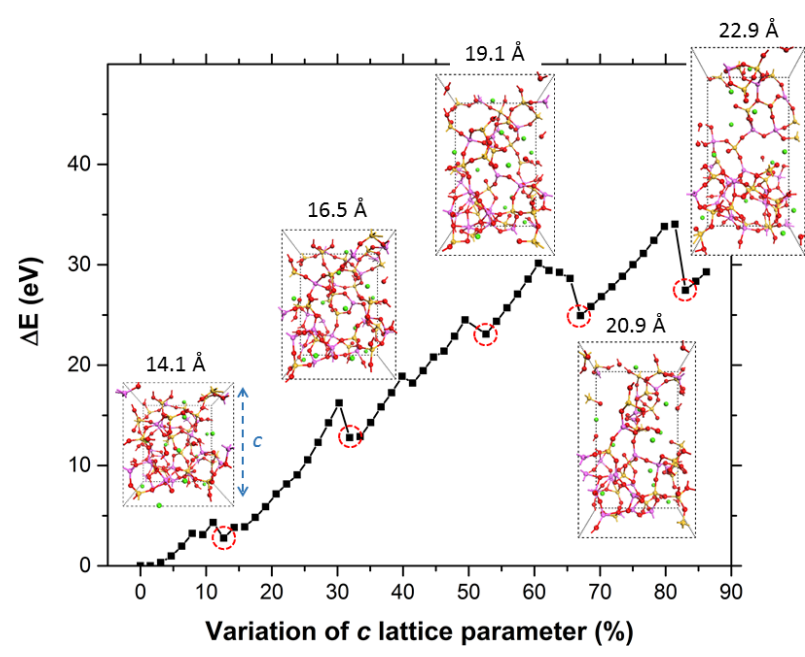

Figure 5. Variation of potential energy in anorthite glass model as a function of lattice parameter $c$ together with the structures of the anorthtite cell at representative values of the lattice parameter.

planes were fixed at $12.51 \AA$. This value corresponds to the optimal (theoretical) lattice parameter obtained from the isotropic relaxation of a cubic cell of anorthite glass.

The value of $c$ was increased with increments of $0.2 \AA$ and the internal coordinates of the system were fully relaxed, for each value of $c$, at the PBE level of theory using the $\mathrm{CP} 2 \mathrm{~K}$ code. The structure of representative structures along the potential energy of anorthite glass are also reported in Figure 5 . The $c$ lattice is extended by as much as $90 \%$ without signs of bond breaking, and during the simulation of the mechanical rupture the glass "recovers" several times, as evidenced by the minima along the potential energy (Figure 5). At $c=22.9 \AA$, there are still bonds connecting the two emerging surfaces but it is possible to notice the formation of a surface with a topology that is certainly different from the flat surface that would be obtained by simply cleaving the bulk structure of anorthite glass. Moreover, the size of the system (156 atoms) and the rupture-induced lattice deformation make these calculations computationally very demanding and therefore of difficult application for the routine generation of surfaces of glassy materials.

\section{Molecular Clusters}

The molecular cluster models of anorthite glass, largecement and small-cement were geometry-optimised to stable structures; confirmed as residing at minima on their respective potential energy hypersurfaces (PEHSs) by analytical frequency determinations (Figures 6, 7, 8, respectively). General structural trends are summarised in Table 2, including Al-coordination and peak values of selected RDFs (Al-O, Si-O, Ca-O).

$\mathrm{Al}(\mathrm{IV})$ prevails in the anorthite (81\%) and small-cement clusters (81\%) relative to the large-cement cluster (67\%), due to the higher number of terminal Al-centres, bound by $-\mathrm{OH}$ groups. The surface polymer groups in the larger cement cluster effectively bind these centres, forming $\mathrm{Al}(\mathrm{V})$ preferred at these matrix interfaces, ${ }^{99,100}$ bringing the value $69 \%$; respectably close to $67 \%$ in the AIMD glass models.
For the $r_{\text {peak }}$ values for the $\mathrm{Al}-\mathrm{O}, \mathrm{Si}-\mathrm{O}$ and $\mathrm{Ca}-\mathrm{O}$, all 3 clusters likewise respectably reproduce the results in the AIMD model of anorthtite glass. A slight compression of the Ca-O distances in the anorthite and small-cement clusters is observed, deriving from the higher number of Al-bound-OH groups, which have higher charge densities than bridging oxygens, resulting in increased interaction with $\mathrm{Ca}^{2+}$ (and thus stronger/shorter bonding).

\section{Anorthite-Cluster:}

Of the $16 \mathrm{Al}$-centres in the anorthite cluster, 3 settled into $\mathrm{Al}(\mathrm{V})$ coordination of square-based pyramidal (SBP) symmetry. The remaining $13 \mathrm{Al}$-centres $(81.25 \%)$ had a 4 coordinated tetrahedral structures (Figure 6 and Table 2).

Table 2. Al(IV) coordination (\%), distances $r_{\text {peak }}(\AA)$ of the $1^{\text {st }}$ peak of the $\mathrm{Al}-\mathrm{O}, \mathrm{Si}-\mathrm{O}, \mathrm{Ca}-\mathrm{O}$ pair distribution functions obtained from the quantum chemical cluster models.

\begin{tabular}{cccc}
\hline & & \multicolumn{2}{c}{ Cement } \\
\cline { 3 - 4 } $\mathrm{Al}(\mathrm{IV}) / \%$ & Anorthite & Large & Small \\
\cline { 2 - 4 } $\mathrm{Al}-\mathrm{O} / \AA$ & 1.78 & 69 & 81 \\
$\mathrm{Si}-\mathrm{O} / \AA$ & 1.63 & $1.63,(1.75)^{\mathrm{a}}$ & 1.78 \\
$\mathrm{Ca}-\mathrm{O} / \AA$ & 2.35 & 2.41 & 1.63 \\
\hline $\mathrm{a}-$ Second minor peak & \multicolumn{3}{c}{2.36} \\
\hline
\end{tabular}

This is contrasted against the $67 \%$ in the bulk AIMD determined structure. This deviation arises from cluster's external (interfacial) Al sites, which prefer 4-coordinate geometry. This is particularly true for Al-centres bound with 2 or 3 hydroxyl moieties $(-\mathrm{OH})$, which are representative of the external edges of the glass in the real systems. These sites are most likely to undergo substitution reactions when under attack by acidic polymers, as in glassy cements. The 2 explicit $\mathrm{H}_{2} \mathrm{O}$ particles included in the model, orientated themselves with one

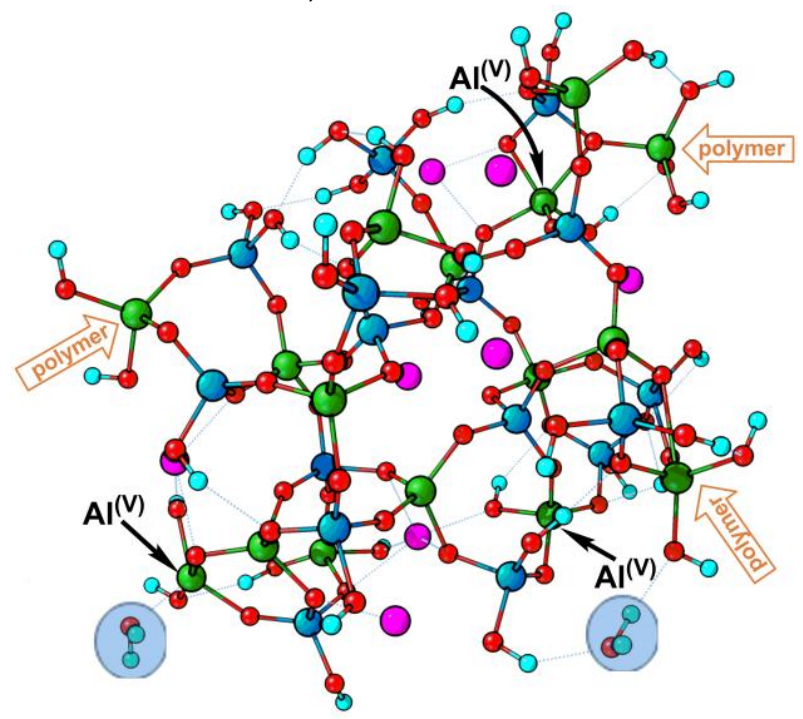

Figure 6. Bare molecular cluster (BMC) of anorthite (8 unit cells, 164 atoms), geometry-optimised and structural identities frequencyconfirmed at the DFT B3LYP/DGDZVP level of theory. Explicit $\mathrm{H}_{2} \mathrm{O}$ particles are indicated by blue circles, 5-coordinate Al-sites by black arrows and $\mathrm{OH}$-rich $\mathrm{Al}$-sites most susceptible to polymer acid-attack by orange arrows. Inter-atomic interactions are indicated by dotted lines. 
forming an $\mathrm{O} \cdots \mathrm{Al}$ interaction, while the other $\mathrm{H}$-bonded two Al-OH groups, bridging the two centres forming an (Al) $\mathrm{OH} \cdots \mathrm{OH}_{2} \cdots \mathrm{OH}(\mathrm{Al})$ interaction (Figure 6, bottom).

\section{Cement Clusters:}

Cement clusters were built through linking oligomers to interfacial -OH groups, mimicking cement formation sites in the real systems. The $\mathrm{OH}$ groups are prone to displacement, particularly in an acidic aqueous environment, such as in glass-polymer cement slurries. For example, the carboxylate groups ( $\left.\mathrm{COO}^{-}\right)$in a polyacrylic acid polymer - as used in some glass cements ${ }^{95,96}$ - will displace one or more $\mathrm{OH}^{\prime}$ s, resulting in the formation of Al-polymer linkages; each $\mathrm{COO}^{-}$acting as a mono- or bi-dentate ligand. During cementation, these substitutions proceed via condensation-like transformations with $\mathrm{H}^{+}$readily available (as $\mathrm{H}_{3} \mathrm{O}^{+}$from polymer solution) forming $\mathrm{H}_{2} \mathrm{O}$ with the departing hydroxyl groups.

The 'large' cement model was formulated based on three such $(\mathrm{OH}) \rightarrow$ polymer substitutions. This was successfully geometry-optimised to a minimum on its respective energy hypersurface (Figure 7); albeit a challenge given the cluster's size and flexibility (see Methods). The majority of the difficulty arising from the flatness of the hypersurface requiring manual assistance to guide the structure to a stable minimum; flexibility arising from the relatively high number of terminal $\mathrm{OH}$ and $\mathrm{CH}_{3}$ groups, each with their own inherent 'floppiness'.

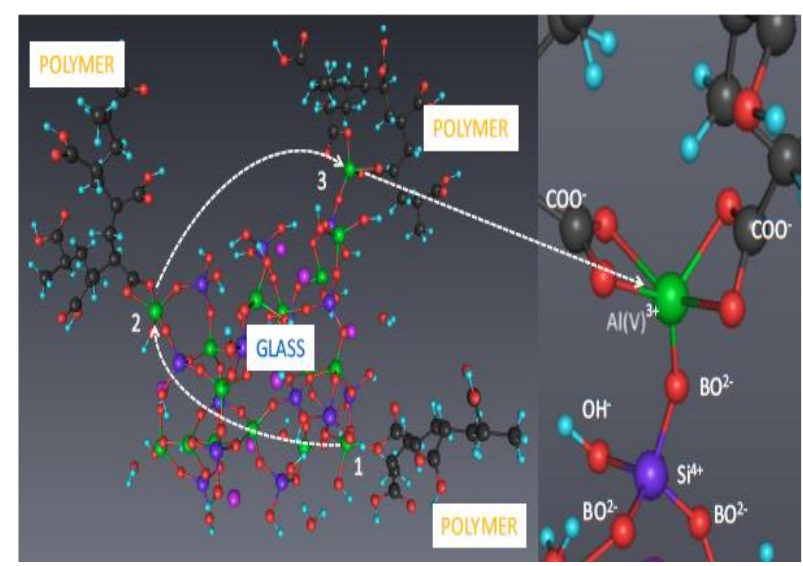

Figure 7. 'Large' cement cluster model, consisting of 322 atoms, geometry-optimised and stability frequency-confirmed at the ab initio $\mathrm{HF} / 3-21 \mathrm{G}$ level of theory. The 3 polymer-bound interfacial Al-linkages are numbered. A close-up of the interfacial heptamer-coordinated Al (\#3, top) is shown on the right-side, together with neighbouring groups and atomic centres.

The optimised cement structure equilibrated its interfacial glass-polymer linkages via $\mathrm{Al}(\mathrm{V})$ centres, settling into square-based pyramidal (SBP) and trigonal bipyramidal (TBP) geometries, for the heptamer and hexamer, respectively. The $3^{\text {rd }}$ oligomer (pentamer) settled into a tetrahedral rarer interfacial AI(IV) linkage; showing the structural diversity possible and for such interfaces.

Overall, this 'large' cluster also proved to be very flexibile with 570 of the 960 total vibrational modes
( $\sim 60 \%)$ falling in the fingerprint region $(<\sim 30 \mathrm{THz}), 68$ ( 7\%) falling within the $\mathrm{THz}$ regime characterised by collective motions $(<\sim 3 \mathrm{THz})$. These dynamics are only taken qualitatively and not further analysed herein due to the HF method not generating physically realistic vibrational dynamics representative of the physical reality.

The smaller cement model was generated by pruning two oligomers from the large cluster and retaining the $\mathrm{Al}(\mathrm{V})$-SBP bound heptamer. This structure also required some manipulative 'dexterity', eventually optimising to a stable structure located at a mimimum on its hypersurface. The AI(V)-SBP geometry of the linkage was retained, with little change to its local geometry (Figure 8). The majority of the geometric frustration is due to the edge-groups, reorganising themselves in the dielectric
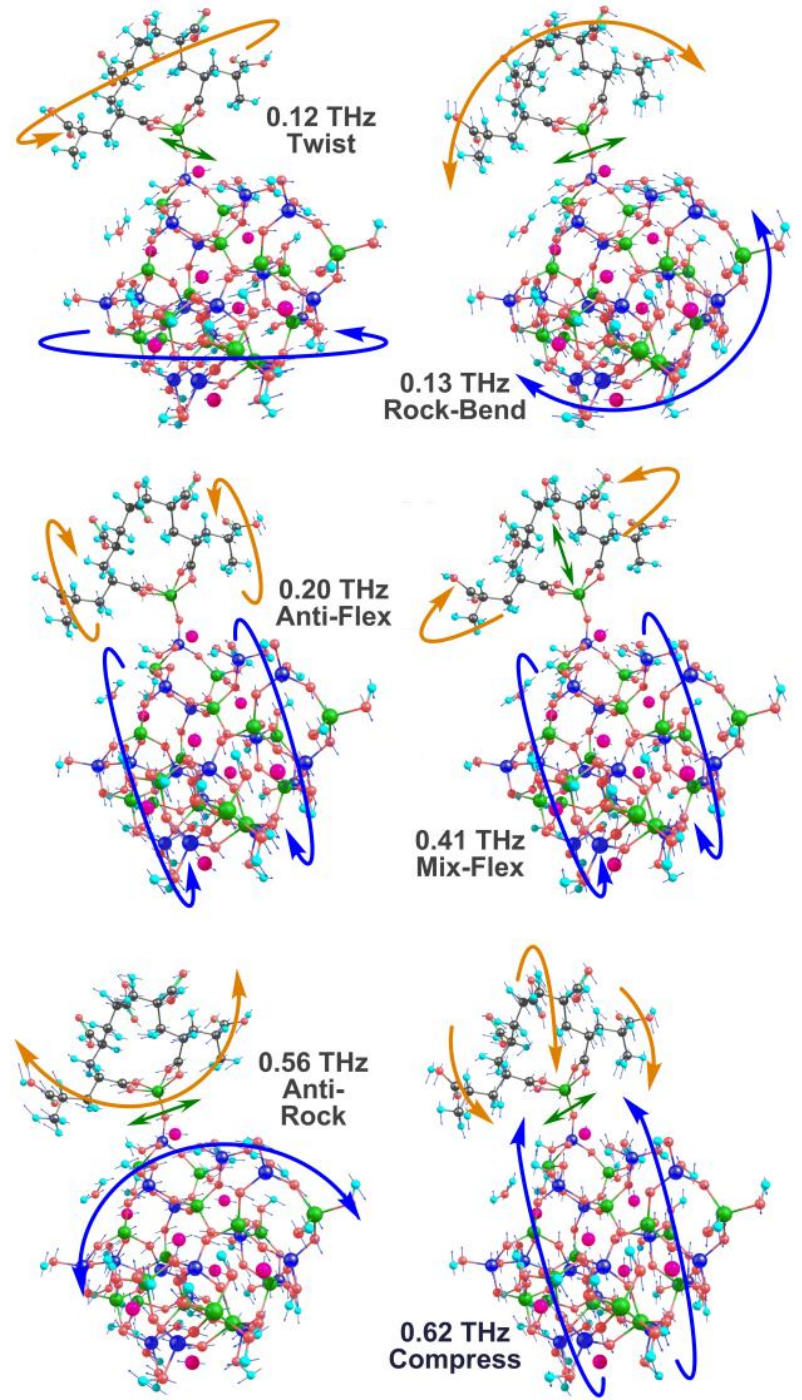

Figure 8. Hybrid cooperative dynamics $(0-1 \mathrm{THz})$ of chelation in 'small' cement model, consisting of 228 atoms, geometryoptimised and stability frequency-confirmed at the DFT B3LYP/DGDZVP level, including explicit $\mathrm{H}_{2} \mathrm{O}$ particles and aqueous solvent-corrections. Analyses of the collective organic-inorganic vibrations reveal rotational, rocking, twisting and wagging actions pivoted centered on a $\mathrm{Al}(\mathrm{V})$ pivot. 
medium of the imposed solvent effects.

The cement cluster, based on a DFT methodology and including solvent effects, represented the most evolved of the cluster models and was therefore candidate for exploring cooperative dynamics in the $\mathrm{THz}$-regine, linked to mechanical properties in glasses. Schematics depicting the frequency and cartesian-identity of the first 6 normal modes of vibration are presented in Figure 8. Each of these involve opposing motions of the two components (glass and oligomer), effectively straining the interfacial link between the glass and oligomer. These are desribed as follows: $0.12 \mathrm{THz}$ (Twist), $0.13 \mathrm{THz}$ (Rock-Bend), 0.20 $\mathrm{THz}$ (Anti-Flex), 0.41 THz (Mix-Flex), 0.56 THz (Anti-Rock), $0.62 \mathrm{THz}$ (Compression). Further exploration of these modes and their relationship with structural and mechanical properties is required and is currently being explored.

Overall, despite being relatively small these unembedded BMCs have performed relatively well with respect to the more common periodic approaches (AIMD in this case) and experimental trends for An glass. Larger versions of the BMCs presented herein would benefit greatly from similar analyses to see where structural and dynamic trends are (un)retained, in addition to tracking the influence of cluster size on interfacial bonding sites. Perhaps most encouraging is the recent successes of EC$\mathrm{MC}$ in characterising heterogeous catalysts, ${ }^{101-102}$ zeolites $^{103}$ and optical materials, ${ }^{104}$ amongst other ordered systems. Further successes with simple disordered systems such as amorphous silica have been successfully so-characterised, ${ }^{105}$ adding confidence to the prospect of formulating EC-MC models of An glasses, through the combination of periodic and cluster models pesented in this work. However, the BMC approach continues to present the most effective way forward to generating models most representative of interfacial structure and dynamics for cementitous materials.

\section{CONCLUSIONS}

We have conducted 3D- and OD-periodic calculations on the crystalline and amorphous forms of the anorthite calcium-aluminosilicate system. Bare molecular cluster models of the anorthite glass were also analysed, along with cement clusters comprising PAA oligomers enclosing the glass cluster. Results show a preference for AI(IV) coordination in the bulk interior of the glass, whilst $\mathrm{Al}(\mathrm{V})$ centres dominate the polymer-glass interfacial sites. A a very slight expansion of $\mathrm{Al}-\mathrm{O}$ bonding, and slight compression of $\mathrm{Ca}-\mathrm{O}$ linkages, relative to experimental results, is observed in both the periodic and cluster models.

Two additional bare cluster models of cement (322 and 228 atoms) were built using oligomers to envelope the glass cluster and structurally optimised. These clusters showed a preference for AI(IV) centres in the bulk interior, yet $\mathrm{Al}(\mathrm{V})$ centres at the glass-polymer interface.

Overall, the bare clusters of anorthite glass and cement successfully provided atomistic details of bonding, and dynamics possibly linked to bulk mechanical properties. Extending the approach to engineer larger glass and cement clusters would lower Surface Area:Volume ratios, effectively burying a larger number of Al centres. Ideally, when BMC sizes approach those of real nano-particles and nano-clusters, the BMC approach will make the PBC and EC-MC approaches obsolete for these systems. Works are ongoing with full $a b$ initio bare molecular clusters of 3-7 $\mathrm{nm}$ a side, effectively approaching the sizes of real nanoclusters.

\section{Acknowledgements}

D.D.T. thanks the UK's Royal Society for the award of a Royal Society Industry Fellowship. This research utilised Queen Mary's MidPlus computational facilities, supported by QMUL Research-IT and funded by EPSRC grant EP/K000128/1. Via our membership of the UK's HEC Materials Chemistry Consortium, which is funded by EPSRC (EP/L000202), this work used the ARCHER UK National Supercomputing Service (http://www.archer.ac.uk).

\section{References}

[1] W.A. Deer, R.A. Howie, J. Zussman, Rock-forming minerals, V. $4 A$, Framework silicates, Feldspar, $2^{\text {nd }}$ edition. Geological Society of London, 2001.

[2] J.A. Wood, J.S. Dickey, Jr., U.B. Marvin, B.N. Powell, Geochimica et Cosmochimica Acta Supplement 1 (1970) 965.

[3] R. Le Parc, B. Champagnon, J. Dianoux, P. Jarry, V. Martinez, J. Non-Cryst. Solids 323 (2003) 155.

[4] E.Ya. Medvedovskii, F.Ya. Kharitonov, Glass Ceramics 47 (1990) 462.

[5] J. K. Martinlinna, Handbook of Oral Biomaterials. CRC press, 2015, US

[6] A.H. Kumar, P.W. McMilan, R.R. Tummala, Glass-ceramic structures and sintered multilayer substrates there of with circuit patterns of gold silver or copper, US Patent No. 4, 30, 324 (17 Nov. 1981).

[7] R.R. Tummala, J. Am. Ceram. Soc. 74 (1991) 895.

[8] C.L. Lo, J.G Duh, B. S. Chiou, W. H. Lee, Mater. Res. Bull. 37 (2002) 1949.

[9] A.D. Wilson, S. Crisp, H.J. Prosser, B.G. Lewis, S.A. Merson, Ind. Eng. Chem. Prod. Res. Dev. 19 (1980) 263.

[10] P.C. Aitcin, CANMET/ACl, Holland Symposium, Warsaw, Poland, May 2007.

[11] D.M. Roy, E.L. White, C.A. Langton, M.W. Grutzeck, AIME International Symposium on Oilfield and Geothermal Chemistry, Houston, TX 1979, pp 153-161.

[12] Y. Han, C.W. Li, C. Bian, S.B. Li, C.A. Wang, J. Eur. Ceram. Soc. 33 (2013) 2573.

[13] M. Sutcu, S. Akkhurt, A. Bayram, U. Uluca, Ceram. Inter. 38 (2012) 1033.

[14] Y. Yang, C. Ronzio, Y.S. Jun, Energy Environ. Sci. 4 (2011) 4596.

[15] D.S. Ngah, J. Ind. Technol. 22 (2014) 583.

[16] E. Bruno, G. Chiari, A. Facchinelli, Acta Crystallogr. B32 (1976) 3270.

[17] D. D. Sun, J. H. Tay, H.K. Cheong, D. L. K. Leung, G. R. Qian, J. Hazard. Mater. 87 (2001) 213.

[18] X.G. Zhang, L. Li, Z.H. Huang, M.H. Fang, X.W. Wu, Y.G. Liu, Advanc Mater. Res. 1058 (2014) 209.

[19] M. Marafi, A. Stanislaus, E. Furimsky, Handbook of spent hydroprocessing catalysts, $1^{\text {st }}$ Ed., Elsevier, 2010.

[20] B. L. Phillips, R. J. Kirckpatrick, Am. Mineral. 77 (1992) 484. [21] H. Xu, P. B. Buseck, M. A. Carpenter, Am. Mineral. 82 (1997) 125.

[22] E. Rybacki, G. Dresen, J. Geophys. Res. Atmosph. 105 (2000) 26017. 
[23] N. Binsted, G.N. Greaves, C.M.B. Henderson, Contrib. Mineral. Petrol. 89 (1985) 103.

[24] A. Dimanov, G. Dresen, J. Geophys. Res. 110 (2005) B07203.

[25] H. Hu, L. Dai, H. Li, K. Hui, J. Li, Solid State Ionics 276 (2015)

136.

[26] S.A.T. Redfern, Miner. Mag. 60 (1996) 493.

[27] P. Richet, M.J. Toplis, C.R. Acad, Sci. Ser. IV t2 (2002) 191.

[28] F. Seifert, B.O. Mysen, D. Virgo, Am. Mineral. 67 (1982) 696.

[29] M. Taylor, G.E. Brown, Geochim. Cosmochim. Acta 43 (1979)

61.

[30] N.A. Morgan, F.J. Spear, Am. Mineral. 86 (2001) 915.

[31] D. Nevins, F. J. Spera, Am. Mineral. 83 (1998), 1220.

[32] A. Bonamartini Corradi, F. Bondioli, V. Cannillo, A. M. Ferrari, I. Lancellotti, M. Montorsi, J. Am. Ceram. Soc. 88 (2005) 714.

[33] N. de Koker, Geochimica et Cosmochimica Acta 74 (2010) 5657.

[34] B.B. Karki, B. Bohara, L. Stixrude, Am. Mineral. 96 (2011) 744

[35] P. V. Sushko, A. L. Shluger, Y. Toda, M. Hirano, H. Hosono, Proc. R. Soc. A 467 (2011) 2066.

[36] C. de Graaf, C. Sousa, R. Broer, J. Mol. Struct. 458 (1999) 53. [37] E.V. Stefanovich, T.N. Truong, J. Phys. Chem. B 102 (1998) 3018.

[38] J.L. Pascual, L. Seijo, J. Chem. Phys. 102 (1995) 5368.

[39] N.G. Lebedev, I.V. Zaporotskova, L.A. Chernozatonskii, Microelectron. Eng. 69 (2003) 511.

[40] S. Kruger, N. Rosch, J. Phys-Condens. Mat. 6 (1994) 8149.

[41] J. Torrasa, J.M. Ricart, P. Vilarrubiasa, J. Fraxedas, J. Cryst. Growth 172 (1997) 106.

[42] P.E. Sinclair, A. de Vries, P. Sherwood, C.R.A. Catlow, R.A. van Santen, J. Chem. Soc. Faraday Trans. 94 (1998) 3401.

[43] B. Yoon, W.D. Luedtke, J.P. Gao, U. Landman, J. Phys. Chem. B 107 (2003) 5882.

[44] R.A. van Santen, J. Mol. Cata. A-Chem. 115 (1997) 405.

[45] K.M. Neymana, F. Illas, Cata. Today 105 (2005) 2.

[46] R.A. van Santen, J. Mol. Cata. A-Chem. 107 (1996) 5.

[47] J.M. Vollmer, E.V. Stefanovich, T.N. Truong, J. Phys. Chem. B 103 (1999) 9415.

[48] D. Berthomieu, S. Krishnamurty, B. Coq, G. Delahay, A. Goursot, J. Phys. Chem. B 105 (2001) 1149.

[49] T. Tüğsüz, M. Doğan, F. Sevin, J. Mol. Struct-THEOCHEM 728 (2005) 103.

[50] R. Rungsirisakun, B. Jansang, P. Pantu, J. Limtrakul, J. Mol. Struct. 733 (2005) 239.

[51] N. Hansen, T. Kerber, J. Sauer, A.T. Bell, F.J. Keil, J. Am. Chem. Soc. 132 (2010) 11525.

[52] V. Van Speybroeck, K. De Wispelaere, J. Van der Mynsbrugge, M. Vandichel, K. Hemelsoet, M. Waroquier, Chem. Soc. Rev. 43 (2014) 7326.

[53] G. Piccini, M. Alessio, J. Sauer, Y.C. Zhi, Y.S. Liu, R. Kolvenbach, A. Jentys, J.A. Lercher, J. Phys. Chem. C 119 (2015) 6128.

[54] M. Pykal, P. Jurečka, F. Karlický, M. Otyepka, Phys. Chem. Chem. Phys. 18 (2016) 6351.

[55] J.E. Lowther, J. Phys. C Solid State 9 (1976) 2519.

[56] J.E. Lowther, J. Phys. C Solid State 10 (1977) 1247.

[57] J.E. Lowther, J. Phys. C Solid State 10 (1977) 2501.

[58] A. Fazzio, J.R. Leite, A.C. Pavao, M.L. De Siqueira, J. Phys. C Solid State 11 (1978) L175.

[59] A. Fazzio, J.R. Leite, M.L. De Siqueira, J. Phys. C Solid State 12 (1979) 513.

[60] A. Fazzio, L.M. Brescansin, M.J. Caldas, J.R. Leite, J. Phys. C Solid State 12 (1979) L831.

[61] A. Fazzio, J.R. Leite, M.L. De Siqueira, J. Phys. C Solid State 12 (1979) 3469.

[62] T. Ikoma, Y. Mochizuki, Jpn. J. Appl. Phys. 24 (1985) L935.

[63] U. Zimmerman, A. Burkhardt, N. Malinowski, U. Naher, T.P. Martin, J. Chem. Phys. 101 (1994) 2244.

[64] M.G. Morse, Chem. Rev. 86 (1986) 1049.
[65] W.A. de Heer, Rev. Mod. Phys. 65 (1993) 611.

[66] G.J. Kramer, A.J.M. de Man, R.A. van. Santen, J. Am. Chem. Soc. 113 (1999) 6435.

[67] R. Orlando, P. Azvant, M.D. Towler, R. Dovesi, C. Roetti. J. Phys.-Condens. Mat. 8 (1996) 1123.

[68] P. Ugliengo, V. Saunders, E. Garrone, J. Phys. Chem. 94 (1990) 2260.

[69] E.H. Teunissen, F.B. van Dujineveldt, R.A. van Santen, J. Phys. Chem. 96 (1992) 366.

[70] E.H. Teunissen, C. Roetti, C. Pisani, A.J.M. de Man, A.P.J. Jansen, R. Orlando, R.A. van Santen, R. Dovesi, Model. Simul. Mater. Sci. Eng. 2 (1994) 921.

[71] C. Sharpe-Tudoran, B. Fricke, J. Anton, J. Chem. Phys. 126 (2007) 1742702.

[72] J.M. Vollmer, E.V. Stefanvoich, T.N. Truong, J. Phys. Chem. B 103 (1999) 9415.

[73] J. limtrakul, S. Jungsuttiwong, P. Khongpracha, J. Mol. Struct. 525 (2000) 153.

[74] D. Geschke, S. Fritzsche, W.D. Sepp, B. Fricke, S. Varga, J. Anton, Phys. Rev. B. 62 (2000) 15439.

[75] J.A. Tossed, J. Phys. Chem. B 109 (2005) 1784.

[76] S.V. Didziulis, K.D. Butcher, S.S. Perry, Inorganic Chem. 42 (2003) 7766.

[77] L.E. Wainwright, J. Starkey, Z. Kristallogr. 133 (1971) 75.

[78] S.J. Clark, M.D. Segall, C.J. Pickard, P.J. Hasnip, M.I.J. Probert, K. Refson, M.C. Payne, Z. Kristallogr. 220 (2005) 567.

[79] J.P. Perdew, K. Burke, M. Ernzerhof, Phys. Rev. Lett. 77 (1996) 3865.

[80] D. Vanderbilt, Phys. Rev. B 41 (1990) 7892.

[81] The CP2K developers group, 2015. CP2K version 2.7 (Development Version). [Online] Available at: http://www.cp2k.org/

[82] J. Hutter, M. Iannuzzi, F. Schiffmann, J. VandeVondele, Comput. Mol. Sci. 4 (2014) 15.

[83] J.K. Christie, A. Tilocca, Adv. Eng. Mater. 12 (2010) B326.

[84] A. Tilocca, Phys. Chem. Chem. Phys 16 (2014) 3874.

[85] P. Ganster, M. Benoit, J.M. Delaye, W. Kob, Mol. Simul. 33 (2007) 1093.

[86] S. Goedecker, M.Teter, J. Hutter, Phys. Rev. B 54 (1996) 1703. [87] A. Tilocca, Phys. Rev. B 76 (2007) 224202.

[88] D. Di Tommaso, R.I. Ainsworth, E. Tang, N.H. de Leeuw, J. Mater. Chem. B 1 (2013) 5054.

[89] R. Knoche, D. B. Dingwell and S. L. Webb, Geochim. Cosmochim. Acta 56 (1992), 689.

[90] C. Lee, W. Yang, R.G. Parr, Phys. Rev. B 37 (1988) 785.

[91] A.D. Becke, J. Chem. Phys. 98 (1993) 5648.

[92] N. Godbout, D.R. Salahub, J. Andzelm, E. Wimmer, Can. J. Chem. 70 (1992) 560.

[93] Gaussian 09, Revision E.01, M.J. Frisch, G.W. Trucks, H.B. Schlegel, G.E. Scuseria, M.A. Robb, J.R. Cheeseman, G. Scalmani, V. Barone, B. Mennucci, G.A. Petersson, H. Nakatsuji, M. Caricato, X. Li, H.P. Hratchian, A.F. Izmaylov, J. Bloino, G. Zheng, J.L. Sonnenberg, M. Hada, M. Ehara, K. Toyota, R. Fukuda, J. Hasegawa, M. Ishida, T. Nakajima, Y. Honda, O. Kitao, H. Nakai, T. Vreven, J.A. Montgomery, Jr., J.E. Peralta, F. Ogliaro, M. Bearpark, J.J. Heyd, E. Brothers, K.N. Kudin, V.N. Staroverov, R. Kobayashi, J. Normand, K. Raghavachari, A. Rendell, J.C. Burant, S.S. Iyengar, J. Tomasi, M. Cossi, N. Rega, J.M. Millam, M. Klene, J.E. Knox, J.B. Cross, V. Bakken, C. Adamo, J. Jaramillo, R. Gomperts, R.E. Stratmann, O. Yazyev, A.J. Austin, R. Cammi, C. Pomelli, J.W. Ochterski, R.L. Martin, K. Morokuma, V.G. Zakrzewski, G.A. Voth, P. Salvador, J.J. Dannenberg, S. Dapprich, A.D. Daniels, Ö. Farkas, J.B. Foresman, J.V. Ortiz, J. Cioslowski, D.J. Fox, Gaussian, Inc., Wallingford CT, 2009.

[94] E. Tang, D. Di Tommaso N.H. de Leeuw, Adv. Eng. Mater. 12 (2010) B331. 
[95] K.V. Tian, B. Yang, Y.Z. Yue, D.T. Bowron, J. Mayers, R.S. Donnan, C. Dobó-Nagy, J.W. Nicholson, D.-C. Fang, A.L. Greer, G.A. Chass, G.N. Greaves, Nat. Commun. 6 (2015) 8631.

[96] K.V. Tian, G. Chass, D. Di Tommaso, Phys. Chem. Chem. Phys. 8 (2016) 83.

[97] S.K. Lee, J.F. Stebbins, Am. Mineral. 84 (1999) 937.

[98] A. Tilocca, A.N. Cormack, ACS Appl. Mater. Inter. 1 (2009) 1324.

[99] A. Tilocca, A.N. Cormack, J. Phys. Chem. C 112 (2008) 11936.

[100] K.V. Tian, P.M. Nagy, G.A. Chass, P. Fejerdy, J.W. Nicholson, I.G. Csizmadia, C. Dobó-Nagy, J. Mater. Sci. Mater. Med. 23 (2012) 677.

[101] A.J. O'Malley, A. J. Logsdail, A.A. Sokola, C.R.A. Catlow, Faraday Discuss. (2016) Advance article.

[102] T.W. Keal, P. Sherwood, G. Dutta, A.A. Sokol, C.R.A. Catlow, PROCEEDINGS OF THE ROYAL SOCIETY A-MATHEMATICAL PHYSICAL AND ENGINEERING SCIENCES 467 (2011) 1900.

[103] D. Berger, A.J. Logsdail, H. Oberhofer, M.R. Farrow, C.R.A. Catlow, P. Sherwood, A.A. Sokol, V. Blum, K. Reuter, J. Chem. Phys. 141 (2014) 024105.

[104] J. Buckeridge, C.R.A. Catlow, D.O. Scanlon, T.W. Keal, P. Sherwood, M. Miskufova, A. Walsh, S.M. Woodley, A.A. Sokol, Phys. Rev. Lett. 114 (2015) 016405.

[105] D. Ricci, G. Pacchioni, M.A. Szymanski, A.L. Shluger, A.M. Stoneham, Phys. Rev. B, 64 (2001) 224104. 